\title{
Optimization of Surface Roughness in Drilling Medium-Density Fiberboard with a Parallel Robot
}

\author{
Elmas Aşkar Ayyıldız $\mathbb{D}^{1},{ }^{1}$ Mustafa Ayyıldız $\mathbb{D}^{2},{ }^{2}$ and Fuat Kara $\mathbb{D}^{2}$ \\ ${ }^{1}$ Department of Mechanical Engineering, Institute of Science, Düzce University, Düzce, Turkey \\ ${ }^{2}$ Mechanical Engineering, Düzce University, Düzce, Turkey \\ Correspondence should be addressed to Fuat Kara; fuatkara@duzce.edu.tr
}

Received 15 December 2020; Revised 29 December 2020; Accepted 2 January 2021; Published 12 January 2021

Academic Editor: Jinyang Xu

Copyright (๐ 2021 Elmas Aşkar Ayyıldız et al. This is an open access article distributed under the Creative Commons Attribution License, which permits unrestricted use, distribution, and reproduction in any medium, provided the original work is properly cited.

\begin{abstract}
This study focuses on the examination of the effect of cutting parameters on surface roughness when drilling medium-density fiberboard (MDF) with a parallel robot. Taguchi technique was applied to find the optimum drilling parameters and, later, the drilling processing. Experimental layout was established using the Taguchi $L_{18}$ orthogonal array, and experimental data were examined via a statistical analysis of variance (ANOVA). Experimental results were performed by multiple regression analysis (linear and quadratic). Correlation coefficient $\left(R^{2}\right)$ was found $99.46 \%$ for surface roughness with the quadratic regression model. By the Taguchi analysis, the optimum values for the surface roughness were found to be a point angle of $118^{\circ}$, a cutting speed of $47.1 \mathrm{~m} / \mathrm{min}$, and a feed rate of $0.01 \mathrm{~mm} / \mathrm{rev}$. The optimization outcomes presented that the Taguchi technique had been successfully performed to decide the optimal surface roughness of the MDF in the drilling.
\end{abstract}

\section{Introduction}

Medium-density fiberboard (MDF) consists of wood fibres and a synthetic binder. Diverse machining processes such as drilling, milling, and turning are applied to obtain the required size and form of the MDF [1-4]. The most common technique for examining machining efficiency is based on the surface finishing and covers visual evaluation of surface quality measurement $[5,6]$. Nowadays, especially, algorithms based on experimental design are used to optimize various engineering problems $[7,8]$. The Taguchi method is an empirical design procedure that greatly reduces the number of experiments using orthogonal arrays and, at the same time, tries to minimize the effects of uncontrollable factors. Optimum process parameters are obtained by a signal-to-noise $(\mathrm{S} / \mathrm{N})$ ratio and analysis of variance (ANOVA) [9-12]. Gaitonde [11] researched the impact of cutting parameters on multiple performance characteristics throughout drilling of the MDF material via the Taguchi method. Both, the feed rate and cutting speed were found to be significant drilling parameters to control delamination using ANOVA.
Palanikumar [13] examined the delamination of the MDF board using orthogonal array, $\mathrm{S} / \mathrm{N}$, and ANOVA. The results showed that the feed rate was the main factor affecting the delamination of the MDF board throughout the drilling process. The authors recommended high spindle speed, low feed rate, and low drill diameter when drilling the MDF boards. Prakash et al. [14] examined the Taguchi method and response surface methodology (RSM) for surface roughness analysis in drilling of medium-density fiberboard panels. Experimental results showed that the most important drilling parameter for surface roughness is feed rate and then cutting speed. Prakash et al. [15] studied the estimation of surface roughness in machining of the MDF material by drilling parameters such as spindle speed, feed rate, and drill diameter using the Taguchi method. Palanikumar and Valarmathi [16] used the Taguchi method, RSM, and ANOVA to estimate the effect of machining parameters on thrust force in drilling of MDF materials. Szwajka et al. [17] examined the influence of the coating type on thrust force, cutting torque, cutting tool temperature, and surface roughness of the hole on the drill cutting blades in drilling MDF panels. The researchers 
analyzed the results of the experiments statistically via a multifactor analysis of variance (ANOVA).

Many papers have been published on optimization of cutting parameters and estimation of shear forces, surface roughness, and damage factor in machining metals [11 and 12] and composites [18-20]. Köklü et al. [18], drilling performance of functionally graded composite (FGC), depending on delamination, thrust force, and vibration, investigated experimentally by using different cutting parameters, which are feed rate, spindle speed, and material directions (carbon/epoxy and glass/epoxy). They used the Taguchi method, ANOVA, and ANN to optimize parameters. Sur and Erkan [19] drilled carbon fibre reinforced plastic (CFRP) composite plates with standard geometry drill bits with different point angles using different cutting parameters and optimized the hole damages with the Taguchi method. Ay et al. [20] examined the drillability performance of the carbon fibre reinforced polymeric composite material using different shear parameters under dry and cryogenic conditions. They used the Gray relational analysis method to determine optimum drilling conditions. In machining, vibrations occur due to changes in parameters such as cutting speed, feed rate, and depth cut applied to the workpiece. Nonlinear interaction between the tool and workpiece leads to the formation of chip formation and consequently to irregularities on the workpiece surface and directly affects the surface roughness quality [21]. Many properties of the MDF have been investigated in numerous studies in the past, but no work has been done on drilling with a parallel robot. The paper combines the Taguchi method and multiple regressions to optimize process parameters in MDF drilling for minimizing surface roughness. Nonetheless, this study was inspired by very limited or no work on the application of the Taguchi method and multiple regressions in this field. For this reason, this work aims to implement a Taguchi $L_{18}$ orthogonal array to make changes as follows: (1) a systematic research of the impact of drilling parameters such as point angle, cutting speed, and feed rate on the MDF surface roughness; (2) optimize these process variables considered to find the lowest drilling surface roughness.

\section{Materials and Methods}

The experiments were realized on a parallel robot with a $0.75 \mathrm{~kW}$ motor spindle and a maximum spindle speed of 24,000 rpm [22]. A MDF material with thickness of $8 \mathrm{~mm}$ was used as the test sample. The MDF is supplied and produced by Turkey. The MDF is commercially convenient and is operated for producing panel doors, flush doors, tables, cabinets, etc. Mechanical and physical properties of the MDF material are demonstrated in Table 1.

The experiments realized in MDF materials using HSS (high-speed steel) drills with $5 \mathrm{~mm}$ of diameter and point angles of $118^{\circ}$ and $135^{\circ}$. The MDF material in the form of $50 \times 50 \times 8 \mathrm{~mm}$ was used as the workpiece. The experimental setup is shown in Figure 1.

The surface roughness was measured with the Mahr Marsurf PS 10. The surface roughness $(R a)$ value was
TABLE 1: Mechanical and physical properties of the MDF material.

\begin{tabular}{lc}
\hline Properties & Value \\
\hline Tensile strength & $0.8 \mathrm{MPa}$ \\
Modulus of rupture & $28 \mathrm{MPa}$ \\
Elasticity modulus & $2800 \mathrm{MPa}$ \\
Humidity & $5-8 \%$ \\
Density & $600-900 \mathrm{~kg} / \mathrm{m}^{3}$ \\
\hline
\end{tabular}

assigned as the mean of three measurements taken from the drilled surfaces. The drilling tests were implemented at three different cutting speeds $(15.7,31.4$, and $47.1 \mathrm{~m} / \mathrm{min})$, three feed rates $(0.01,0.03$, and $0.05 \mathrm{~mm} / \mathrm{rev})$, and two point angles $\left(118^{\circ}\right.$ and $\left.135^{\circ}\right)$.

\section{Experimental Design}

3.1. Taguchi Method. The Taguchi method improved by Taguchi has been used in engineering analysis to optimize performance characteristics by adjusting design parameters [9]. Also, the Taguchi method offers a simple and effective systematic approach to optimize designs in terms of quality, performance, and cost. By using the Taguchi method based on orthogonal arrays, time and cost can be reduced. Taguchi recommends using signal-to-noise $(\mathrm{S} / \mathrm{N})$ ratio $(\eta)$ to determine the quality characteristics applied to engineering design problems. There are generally three types of quality characteristics; the lower the better, the nominal the best, and the higher the better [23]. In this work, the lower the better quality characteristic was used to minimize surface roughness:

$$
\eta=\left(\frac{S}{N}\right)=-10 \log \left[\frac{1}{N} \sum_{i=1}^{n} y_{i}^{2}\right],
$$

where $n$ is the number of data of the experiment and $y_{i}$ is the measured data at the $i$ th experiment [24]. In addition to the signal-to-noise ratio, a statistical analysis of variance (ANOVA) was employed to demonstrate the impact of process parameters on surface roughness. Drilling parameters and their levels considered in this work are demonstrated in Table 2. The empirical layout for the three cutting parameters via full factorial design by orthogonal array of Taguchi $L_{18}\left(2^{1} \times 3^{2}\right)$ is demonstrated in Table 3 .

3.2. Multiple Regression Method. Regression analysis proposed by Galton examines the statistical relationship between one or more independent variables and dependent variables [25]. In addition, multiple regressions are a collection of mathematical and statistical techniques beneficial for modeling and analyzing problems in which the response of interest is affected by several variables [26]. In this study, the empirical data was used to construct a linear and quadratic model by the regression method. The independent variables were point angle $(\alpha)$, cutting speed $(V)$, and feed rate $(f)$, whereas the dependent variable was surface roughness $(R a)$. Multiple regression analysis was operated to obtain the predict equation (the linear and quadratic model) for $R a$, as seen in equations (2) and (3), respectively [27]: 


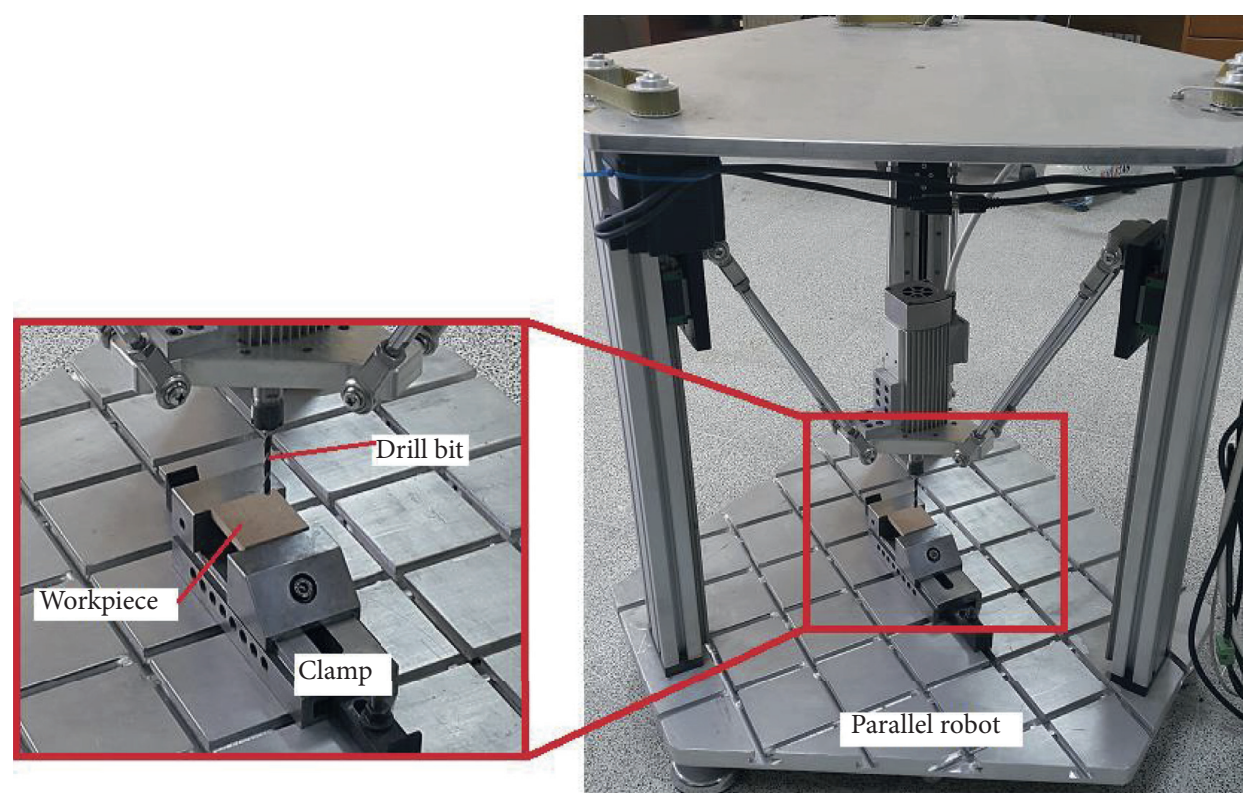

Figure 1: The experimental setup.

Table 2: Drilling parameters and their levels.

\begin{tabular}{lcccc}
\hline Parameters & Symbol & Level 1 & Level 2 & Level 3 \\
\hline Point angle & A & 118 & 135 & - \\
Cutting speed $(\mathrm{m} / \mathrm{min})$ & $\mathrm{B}$ & 15.7 & 31.4 & 47.1 \\
Feed rate $(\mathrm{mm} / \mathrm{rev})$ & C & 0.01 & 0.03 & 0.05
\end{tabular}

TABLE 3: Full factorial design with orthogonal array of Taguchi $L_{18}$ $\left(2^{1} \times 3^{2}\right)$.

\begin{tabular}{lccc}
\hline Experiment no. & Factor A & Factor B & Factor C \\
\hline 1 & 1 & 1 & 1 \\
2 & 1 & 1 & 2 \\
3 & 1 & 1 & 3 \\
4 & 1 & 2 & 1 \\
5 & 1 & 2 & 2 \\
6 & 1 & 2 & 3 \\
7 & 1 & 3 & 1 \\
8 & 1 & 3 & 2 \\
9 & 1 & 3 & 3 \\
10 & 2 & 1 & 1 \\
11 & 2 & 1 & 2 \\
12 & 2 & 1 & 3 \\
13 & 2 & 2 & 1 \\
14 & 2 & 2 & 2 \\
15 & 2 & 2 & 3 \\
16 & 2 & 3 & 1 \\
17 & 2 & 3 & 2 \\
18 & 2 & 3 & 3 \\
\hline
\end{tabular}

$$
\begin{aligned}
y_{l}= & \beta_{0}+\beta_{1} \alpha+\beta_{2} V+\beta_{3} f, \\
y_{q}= & \beta_{0}+\beta_{1} V+\beta_{2} f+\beta_{3} \alpha+\beta_{4} V^{2}+\beta_{5} f^{2}+\beta_{6} \alpha^{2} \\
& +\beta_{7} V f+\beta_{8} V \alpha+\beta_{9} f \alpha,
\end{aligned}
$$

where $\beta_{0}, \beta_{1}, \ldots, \beta_{9}$ are coefficients used to predict in the multiple regression. The experimental design and statistical analysis were applied by Minitab 18 software.

\section{Results and Discussion}

4.1. Analysis of the $\mathrm{S} / \mathrm{N}$ Ratio. The $\mathrm{S} / \mathrm{N}$ ratios were calculated using equation (1) for each of the 18 trials, and the values are presented in Table 4 along with their experimentally measured values. Valarmathi et al. [28] reported that when drilling MDF panels with drills with different point angles, the surface roughness value decreases by selecting the low tip angle, low feed rate, and high cutting speed. Similarly, when Table 4 is studied, it can be seen that the drill bits using a point angle of $118^{\circ}$ generally exhibited lower surface roughness values than the drill bits using a point angle of $135^{\circ}$. The results demonstrate that the surface roughness increases with the increase of feed rate, whereas the increase of cutting speed reduces the surface roughness.

The average value of the surface roughness was found to be $3.759 \mu \mathrm{m}$ at the end of the drilling tests. The same, average value of $\mathrm{S} / \mathrm{N}$ ratio for surface roughness was found to be $-11.2392 \mathrm{~dB}$. Analysis of the effect of each control factor $(C t$, $V$, and $f$ ) on the surface roughness has been implemented with the $\mathrm{S} / \mathrm{N}$ ratio response table in Table 5 . The level values of control factors for $R a$ depicted in Table 5 are demonstrated in graph forms in Figure 2. These figures demonstrate the level to be chosen for the optimum drilling parameters (the level with the highest point on the graphs) and, at the same time, the relative influence each parameter has on the $\mathrm{S} / \mathrm{N}$ ratio. The best surface roughness values were specified as factor $\mathrm{A} 1(\mathrm{~S} / \mathrm{N}=-10.321)$, factor $\mathrm{B} 3(\mathrm{~S} / \mathrm{N}=-9.900)$, and factor $\mathrm{C} 1(\mathrm{~S} / \mathrm{N}=-9.289)$. The optimal values for the surface roughness assigned for the point angle, cutting speed, and feed rate were $118^{\circ}, 47.1 \mathrm{~m} / \mathrm{min}$, and $0.01 \mathrm{~mm} / \mathrm{rev}$, respectively (Figure 2). As seen in the $\mathrm{S} / \mathrm{N}$ ratio impact graphs, the 
TABLE 4: The results of experiments and $\mathrm{S} / \mathrm{N}$ ratio values.

\begin{tabular}{lccccc}
\hline & \multicolumn{3}{c}{ Control factors } & & \\
Experiment no. & A & B & C & Surface roughness, $R a(\mu \mathrm{m})$ & S/N ratio for $R a(\mathrm{~dB})$ \\
& Point angle $(\alpha)$ & Cutting speed $(V)$ & Feed rate $(f)$ & 3.08 & --9.7710 \\
\hline 1 & 118 & 15.7 & 0.01 & 4.072 & -12.1962 \\
2 & 118 & 15.7 & 0.03 & 4.862 & -13.7363 \\
3 & 118 & 15.7 & 0.05 & 2.479 & -7.8855 \\
4 & 118 & 31.4 & 0.01 & 3.269 & -10.2883 \\
5 & 118 & 31.4 & 0.03 & 4.186 & -12.436 \\
6 & 118 & 31.4 & 0.05 & 2.122 & -6.5349 \\
7 & 118 & 47.1 & 0.01 & 2.883 & -9.1968 \\
8 & 118 & 47.1 & 0.03 & 3.486 & -10.8465 \\
9 & 118 & 47.1 & 0.05 & 3.837 & -11.6798 \\
10 & 135 & 15.7 & 0.01 & 4.886 & -13.7791 \\
11 & 135 & 15.7 & 0.03 & 5.864 & -15.3639 \\
12 & 135 & 15.7 & 0.05 & 3.249 & -10.235 \\
13 & 135 & 31.4 & 0.01 & 3.975 & -11.9867 \\
14 & 135 & 31.4 & 0.03 & 4.758 & -13.5485 \\
15 & 135 & 31.4 & 0.05 & 3.029 & -10.6259 \\
17 & 135 & 47.1 & 0.01 & 3.43 & -12.4898 \\
18 & 135 & 47.1 & 0.03 & 4.212 & \\
\hline
\end{tabular}

TABle 5: The S/N response table for $R a$ factor.

\begin{tabular}{lccc}
\hline & \multicolumn{3}{c}{ Control factors } \\
Level & S & Surface roughness $(R a)$ & \\
& -10.321 & -12.754 & -9.289 \\
Level 1 & -12.157 & -11.063 & -11.359 \\
Level 2 & - & -9.900 & -13.070 \\
Level 3 & 1.836 & 2.854 & 3.781 \\
Delta & &
\end{tabular}

feed rate is demonstrated to have a potent influence on surface roughness and its $\mathrm{S} / \mathrm{N}$ ratios.

4.2. Analysis of Variance. The analysis of variance (ANOVA) is used to determine the effects of design parameters on performance characteristics. In this work, the application of ANOVA, the percent contribution ratio (PCR) of surface roughness is investigated, and the ANOVA conclusions for surface roughness are demonstrated in Table 6 . This analysis was performed at a $5 \%(P<0.05)$ significance level and a $95 \%$ confidence level to identify the drilling parameters that affect the surface roughness. For the control factors to be statistically significant on the output, the $P$ value should be less than 0.05 , and the control factor with the highest $F$ value is considered to be the most effective factor [29]. When Table 6 is examined, the PCR of the A, B, and C factors on the surface roughness reached to be $16.89 \%, 30.99 \%$, and $50.18 \%$, respectively. The feed rate (factor C, 50.18\%) was determined as the most significant factor affecting surface roughness.

4.3. Multiple Regression Analysis of Surface Roughness. In this study, multiple regression analysis for both linear and quadratic regression models was used for the purpose of estimating surface roughness $(R a)$ under the effect of parameters such as point angle $(\alpha)$, cutting speed $(V)$, and feed rate $(f)$. The linear regression model equation obtained for surface roughness is given below:

$$
R a_{l}=-1.820+0.04445 \alpha-0.03949 V+39.88 f .
$$

The comparison of empirical and estimated values obtained with the linear regression model is specified in Figure $3 . \mathrm{R}^{2}$ value of the equation obtained by the linear regression model for $R a$ was found to be $97.37 \%$. The quadratic regression model equation obtained for surface roughness is given below:

$$
\begin{aligned}
R a_{q}= & -2.96-0.0344 V+62.3 f+0.05413 \alpha+0.000653 V^{2} \\
& +28 f^{2}-0.502 V f-0.000245 V \alpha-0.066 f \alpha .
\end{aligned}
$$

The comparison of empirical and estimated values obtained with the quadratic regression model is specified in Figure 4 . The $R^{2}$ value of the equation obtained by the quadratic regression model for $R a$ was reached to be $99.46 \%$. As a result, the quadratic regression model gave better results than the linear regression model and proved to be successful in predicting surface roughness.

4.4. Optimization of Surface Roughness. Optimized parameters must be verified to estimate optimal surface roughness [29]. For this purpose, a confirmation experiment by using the Taguchi optimization technique was performed. Equation (6) was used in order to find the optimum surface roughness [30]:

$$
\mathrm{Ra}_{\text {opt }}=\left(A_{1}-T_{R a}\right)+\left(B_{3}-T_{R a}\right)+\left(C_{1}-T_{R a}\right)+T_{R a},
$$

where $\left(A_{1}, B_{3}\right.$, and $\left.C_{1}\right)$ show the optimal-level mean values of surface roughness $\left(\mathrm{Ra}_{\mathrm{opt}}\right)$ in Table 2 and $T_{R a}$ declares the 


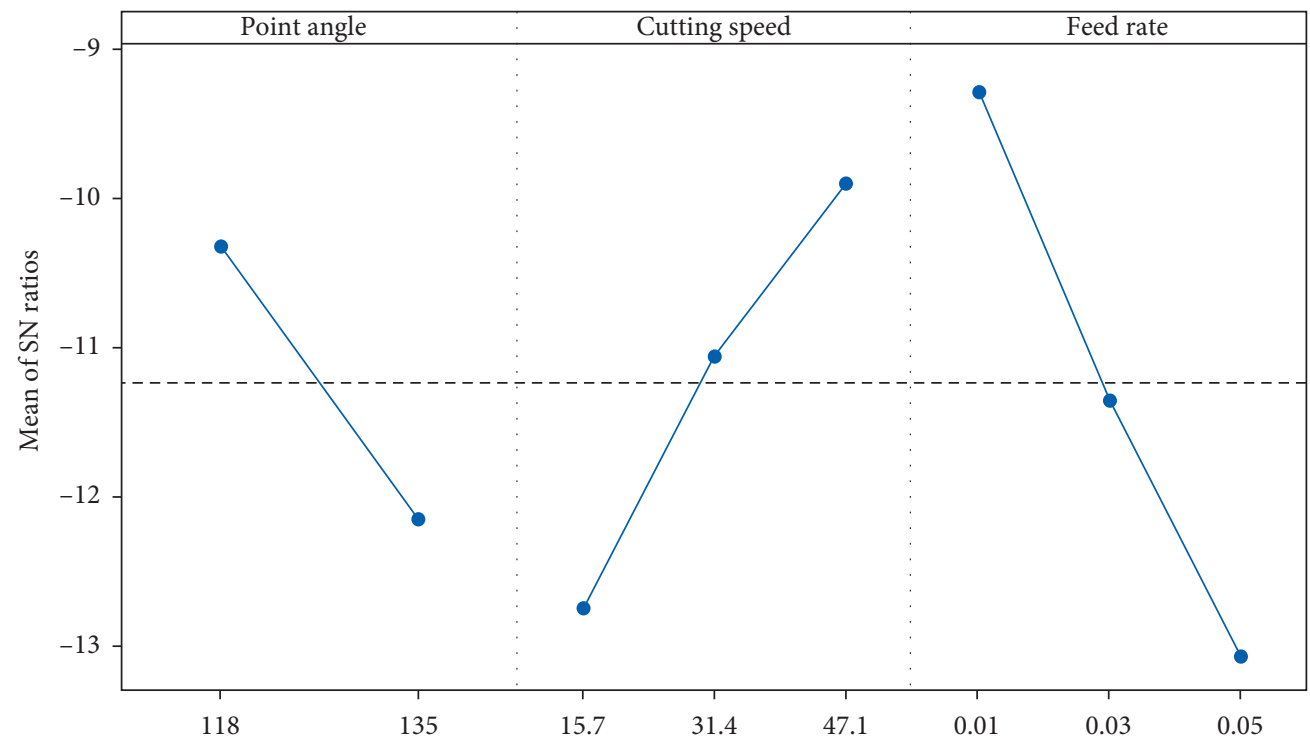

FIgURE 2: The effect of process parameters on average $\mathrm{S} / \mathrm{N}$ ratio for $R a$.

TABLE 6: Results of ANOVA for surface roughness.

\begin{tabular}{|c|c|c|c|c|c|c|}
\hline Variance source & Degree of freedom (DoF) & Sum of squares (SS) & PCR (\%) & Mean of squares (MS) & $F$ ratio & $P$ value \\
\hline \multicolumn{7}{|l|}{$R a$} \\
\hline A & 1 & 2.5696 & 16.89 & 2.56964 & 104.21 & 0.001 \\
\hline B & 2 & 4.7151 & 30.99 & 2.35757 & 95.61 & 0.001 \\
\hline C & 2 & 7.6358 & 50.18 & 3.81788 & 154.83 & 0.001 \\
\hline Error & 12 & 0.2959 & 1.94 & 0.02466 & & \\
\hline Total & 17 & 15.2165 & 100.00 & & & \\
\hline
\end{tabular}

Bold values show the most influential factor.

mean of whole of the surface roughness value obtained from Table 7. According to these equations, the minimum surface roughness can be found as $2.022 \mu \mathrm{m}$.

The results of the confirmation experiment performed with Table 7 are evaluated, taking into account the confidence interval (CI) value calculated by equations (7) and (8) [30]:

$$
\begin{aligned}
\mathrm{CI}_{R a, a} & =\sqrt{F_{\alpha, 1, f e} V_{e}\left[\frac{1}{n_{\mathrm{eff}}}+\frac{1}{R}\right]}, \\
n_{\mathrm{eff}} & =\frac{N}{1+T_{\mathrm{dof}}},
\end{aligned}
$$

where $T_{\mathrm{dof}}$ is the total main factor degrees of freedom, $N$ is the total number of experiments, $n_{\text {eff }}$ is the effective number of replications, $R$ is the number of replications for confirmation experiments, $V_{e}$ is error variance, $f e$ is the degrees of freedom of error, $\alpha$ is the significance level, $F_{\alpha, 1, f e}$ is the $\mathrm{F}$ ratio at a 95 percent CI. $F_{0.05,1,12}=4.747$ (from $F$ test table), $V_{e R a}=0.02466$ (Table 6), $R=3, N=18, T_{\mathrm{dof}}=5$, and $n_{\mathrm{eff}}=3$. The confidence intervals were calculated as $\mathrm{CI}_{\mathrm{Ra}}= \pm 0.279$. The mean optimal $\mathrm{Ra}$ (CI 95 percent) is given as follows:

$$
\begin{aligned}
\left(\mathrm{Ra}_{\text {opt }}-\mathrm{CI}_{\mathrm{Ra}}\right) & <\mathrm{Ra}_{\text {exp }}<\left(\mathrm{Ra}_{\text {opt }}-\mathrm{CI}_{\mathrm{Ra}}\right)=(2.022-0.279) \\
& <2.122<(2.022+0.279)=1.743 \\
& <2.122<2.301
\end{aligned}
$$

The empirical value of $\mathrm{Ra}_{\exp }$ was within admissible $\mathrm{CI}$ limits. As a result, the system for surface roughness was successfully optimized by the Taguchi technique $(P=0.05)$. Estimated values and confirmation test conclusions by Taguchi technique and regression values are specified in Table 8 . The estimated values and empirical values are very close to each other. When the confirmation test results are studied, it can be said that the conclusions obtained are sufficient and Taguchi optimization is successful. 


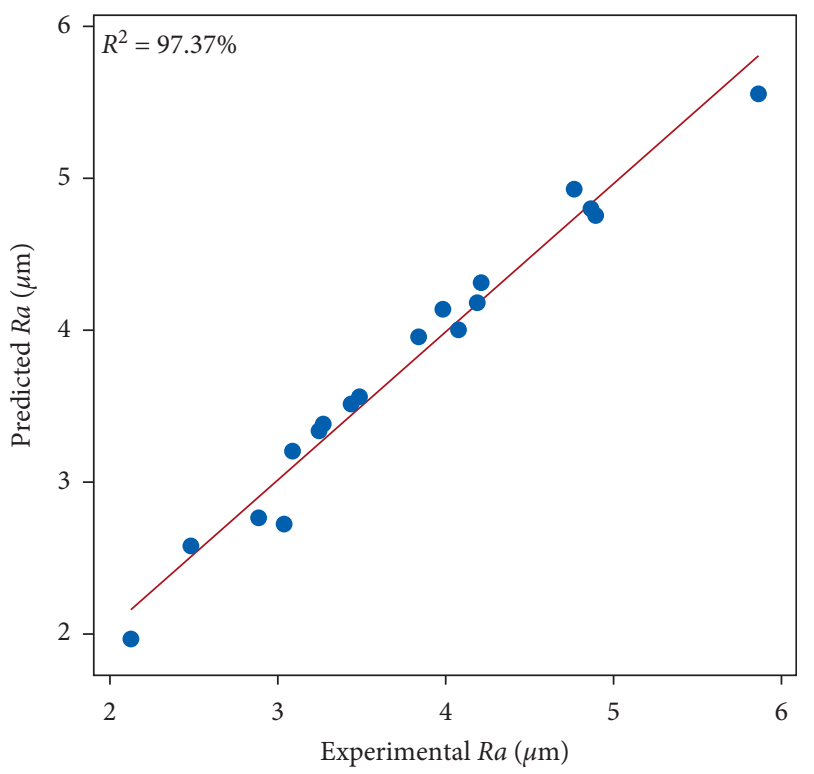

FIGURE 3: Comparison of surface roughness between predicted and experimental values by the linear regression model.

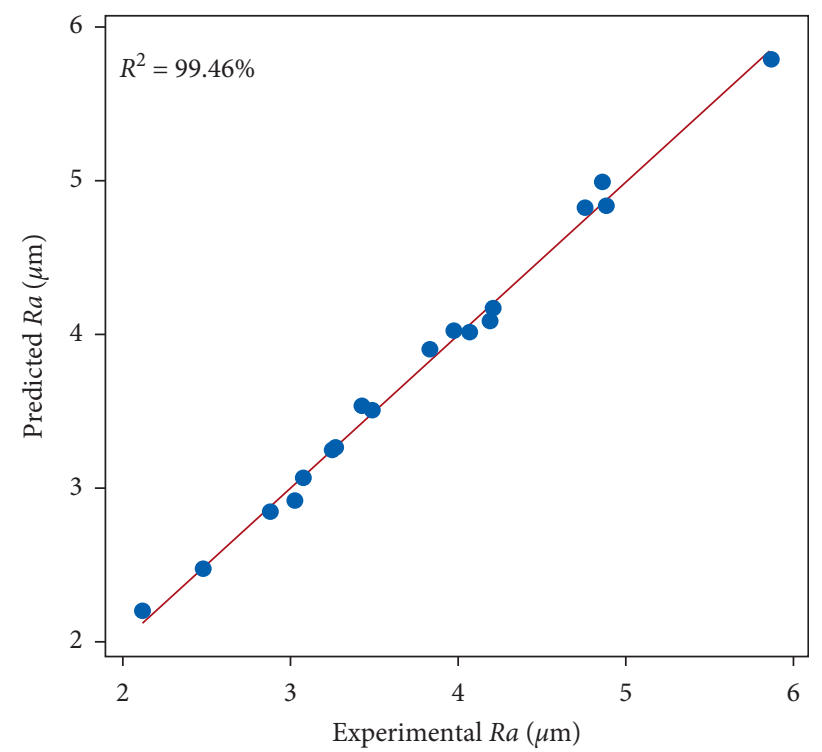

Figure 4: Comparison of surface roughness between predicted and experimental values by the quadratic regression model.

TABLE 7: The mean response table for $R a$ factor.

\begin{tabular}{lccr}
\hline Level & \multicolumn{2}{c}{ Control factors } \\
& A & Surface roughness $(R a)$ & C \\
\hline Level 1 & $\mathbf{3 . 3 8 2}$ & 4.433 & $\mathbf{2 . 9 6 6}$ \\
Level 2 & 4.138 & 3.653 & 3.752 \\
Level 3 & - & $\mathbf{3 . 1 9 4}$ & 4.561 \\
Delta & 0.756 & 1.240 & 1.595 \\
\hline
\end{tabular}


TABLE 8: Estimated values and confirmation test results by Taguchi technique and regression values.

\begin{tabular}{|c|c|c|c|c|c|c|c|c|c|}
\hline \multirow{2}{*}{ Level } & \multicolumn{3}{|c|}{ Taguchi method } & \multicolumn{3}{|c|}{ Linear regression method } & \multicolumn{3}{|c|}{ Quadratic regression method } \\
\hline & Exp. & Pred. & Error (\%) & Exp. & Pred. & Error (\%) & Exp. & Pred. & Error $(\%)$ \\
\hline$R a(\mu \mathrm{m})$ & & & & & & & & & \\
\hline $\mathrm{A}_{1} \mathrm{~B}_{3} \mathrm{C}_{1}$ (optimum) & 2.122 & 2.012 & 5.18 & 2.122 & 1.964 & 7.44 & 2.122 & 2.201 & 3.72 \\
\hline $\mathrm{A}_{2} \mathrm{~B}_{2} \mathrm{C}_{3}$ (random) & 4.758 & 4.834 & 1.59 & 4.758 & 4.935 & 3.72 & 4.758 & 4.820 & 1.30 \\
\hline
\end{tabular}

\section{Conclusions}

In this paper, the MDF material is drilled via different cutting parameters and drill bits. The experimental layout was established according to the Taguchi $L_{18}$ orthogonal array. The Taguchi technique is applied to obtain the optimal drilling parameters and, later, the drilling and experimental conclusions were examined via ANOVA. The conclusions of the experiment are given below:

(i) By using $\mathrm{S} / \mathrm{N}$, the optimal values for the surface roughness assigned for the point angle, cutting speed, and feed rate were $118^{\circ}, 47.1 \mathrm{~m} / \mathrm{min}$, and $0.01 \mathrm{~mm} / \mathrm{rev}$, respectively $\left(\mathrm{A}_{1} \mathrm{~B}_{3} \mathrm{C}_{1}\right)$.

(ii) According to the variance analysis, the PCR of the $\mathrm{A}, \mathrm{B}$, and $\mathrm{C}$ factors on the surface roughness were found to be $16.89 \%, 30.99 \%$, and $50.18 \%$, respectively. The feed rate (factor C, 50.18\%) was determined as the most important factor affecting surface roughness.

(iii) The $R^{2}$ values of the equations attained via the quadratic regression model for $R a$ was found to be $99.46 \%$. As a result, the quadratic regression model gave better results than the linear regression model and proved to be successful in predicting surface roughness.

The optimization outcomes showed that the Taguchi technique had been successfully performed to decide the optimal surface roughness of the MDF material in the drilling operation.

\section{Data Availability}

The data used to support the findings of this study are available from the corresponding author upon request and within the article.

\section{Conflicts of Interest}

The authors declare that they have no conflicts of interest.

\section{References}

[1] S. Prakash, J. L. Mercy, M. K. Salugu, and K. S. M. Vineeth, "Optimization of drilling characteristics using grey relational analysis (GRA) in medium density fiber board (MDF)," Materials Today: Proceedings, vol. 2, no. 4-5, pp. 1541-1551, 2015.

[2] Y. Benlatreche, C. Nouveau, R. Marchal, J. P. F. Martins, and H. Aknouche, "Applications of CrAlN ternary system in wood machining of medium density fibreboard (MDF)," Wear, vol. 267, no. 5-8, pp. 1056-1061, 2009.
[3] K. H. Koc, E. S. Erdinler, E. Hazir, and E. Öztürk, "Effect of CNC application parameters on wooden surface quality," Measurement, vol. 107, pp. 12-18, 2017.

[4] J. Dippon, H. Ren, F. B. Amara, and Y. Altintas, "Orthogonal cutting mechanics of medium density fiberboards," Forest Products Journal, vol. 50, no. 7-8, pp. 25-30, 2000.

[5] A. J. Souza, T. D. Jeremias, A. R. Gonzalez, and H. J. Amorim, "Assessment of melamine-coated MDF surface finish after peripheral milling under different cutting conditions," European Journal of Wood and Wood Products, vol. 77, no. 4, pp. 559-568, 2019.

[6] M. Ayyildiz, "Modeling for prediction of surface roughness in milling medium density fiberboard with a parallel robot," Sensor Review, vol. 39, no. 5, pp. 716-723, 2019.

[7] S. D. Sofuoglu, "Determination of optimal machining parameters of massive wooden edge glued panels which is made of Scots pine Pinus sylvestris L.) using Taguchi design method," European Journal of Wood and Wood Products, vol. 75, no. 1, pp. 33-42, 2017.

[8] E. Hazir and K. H. Koc, "Optimization of wood machining parameters in CNC routers: Taguchi orthogonal array based simulated angling algorithm," Maderas. Ciencia $Y$ Tecnología, vol. 21, no. 4, pp. 493-510, 2019.

[9] G. Taguchi, E. Elsayed, and T. Hsiang, Quality Engineering in Production System Taguchi, McGraw-Hill, New York, NY, USA, 1989.

[10] F. Kara, "Taguchi optimization of surface roughness and flank wear during the turning of DIN 1.2344 tool steel," Materials Testing, vol. 59, no. 10, pp. 903-908, 2017.

[11] M. Kurt and U. Köklü, "Minimization of the shape error in the interrupted grinding process by using Taguchi method," Mechanics, vol. 18, no. 6, pp. 677-682, 2012.

[12] U. Köklü, "Optimisation of machining parameters in interrupted cylindrical grinding using the Grey-based Taguchi method," International Journal of Computer Integrated Manufacturing, vol. 26, no. 8, pp. 696-702, 2013.

[13] V. N. Gaitonde, S. R. Karnik, and J. P. Davim, "Taguchi multiple-performance characteristics optimization in drilling of medium density fibreboard (MDF) to minimize delamination using utility concept," Journal of Materials Processing Technology, vol. 196, no. 1-3, pp. 73-78, 2008.

[14] K. Palanikumar, S. Prakash, and N. Manoharan, "Experimental investigation and analysis on delamination in drilling of wood composite medium density fiber boards," Materials and Manufacturing Processes, vol. 24, no. 12, pp. 1341-1348, 2019.

[15] S. Prakash, J. L. Mercy, and K. Goswami, “A systemic approach for evaluating surface roughness parameters during drilling of medium density fiberboard using Taguchi method," Indian Journal of Science and Technology, vol. 7, no. 11, pp. 1888-1894, 2014.

[16] K. Palanikumar and T. N. Valarmathi, "Experimental investigation and analysis on thrust force in drilling of wood composite medium density fiberboard panels," Experimental Techniques, vol. 40, no. 1, pp. 391-400, 2016. 
[17] K. Szwajka, J. Zielińska-Szwajka, and T. Trzepiecinski, "Experimental study on drilling MDF with tools coated with TiAlN and ZrN," Materials, vol. 12, no. 3, p. 386, 2019.

[18] U. Köklü, M. Mayda, S. Morkavuk, A. Avc1, and O. Demir, "Optimization and prediction of thrust force, vibration and delamination in drilling of functionally graded composite using Taguchi," ANOVA and ANN Analysis," Materials Research Express, vol. 6, no. 8, Article ID 085335, 2019.

[19] G. Sur and Ö. Erkan, "Cutting tool geometry in the drilling of CFRP composite plates and Taguchi optimisation of the cutting parameters affecting delamination," Sigma Journal of Engineering and Natrural Sciences, vol. 36, no. 3, pp. 619-628, 2018.

[20] M. Ay, G. Basmaci, A. Said Yoruk, and A. Etyemez, "Optimization of drilling of carbon fiber reinforced polymer with the grey-based method," Acta Physica Polonica A, vol. 137, no. 4, pp. 535-538, 2020.

[21] G. Litak, "Chaotic vibrations in a regenerative cutting process," Chaos, Solitons \& Fractals, vol. 13, no. 7, pp. 1531-1535, 2002.

[22] E. Aşkar Ayyıldız and M. Ayyıldız, "Development of a 3-axis parallel kinematic machine for milling wood material-Part 1: design,” BioResources, vol. 12, no. 4, pp. 9326-9337, 2017.

[23] M. S. Phadke, Quality Engineering Using Robust Design, Prentice-Hall, Englewoodcliffs, NJ, USA, 1989.

[24] F. Kara, U. Köklü, and U. Kabasakaloğlu, "Taguchi optimization of surface roughness in grinding of cryogenically treated AISI 5140 steel," Materials Testing, vol. 62, no. 10, pp. 1041-1047, 2020.

[25] F. Galton, "Regression towards mediocrity in hereditary stature," The Journal of the Anthropological Institute of Great Britain and Ireland, vol. 15, pp. 246-263, 1886.

[26] D. C. Montgomery, Design and Analysis of Experiments, John Wiley, New York, NY, USA, 2nd, 1984.

[27] I. Asiltürk and M. Çunkaş, "Modeling and prediction of surface roughness in turning operations using artificial neural network and multiple regression method," Expert Systems with Applications, vol. 38, no. 5, pp. 5826-5832, 2011.

[28] T. N. Valarmathi, K. Palanikumar, and S. Sekar, "Modeling of surface roughness in drilling of MDF panels," Applied Mechanics and Materials, vol. 766-767, pp. 831-836, 2015.

[29] F. Kara and B. Öztürk, "Comparison and optimization of PVD and CVD method on surface roughness and flank wear in hard-machining of DIN 1.2738 mold steel," Sensor Review, vol. 39, no. 1, pp. 24-33, 2019.

[30] M. Günay and E. Yücel, “Application of Taguchi method for determining optimum surface roughness in turning of highalloy white cast iron," Measurement, vol. 46, no. 2, pp. 913919, 2013. 